\title{
What Quantitative Anatomy Can Provide for Kinetics of Xylogenesis: Analysis of Cell Radial Diameters
}

\author{
Mikhail S. Zharkov**, \\ Liliana V. Belokopytova ${ }^{\mathrm{b}}$, Marina V. Fontia, \\ Elena A. Babushkina ${ }^{\mathrm{b}}$ and Eugene A. Vaganov ${ }^{\mathrm{a}}$ \\ ${ }^{a}$ Siberian Federal University \\ Krasnoyarsk, Russian Federation \\ ${ }^{b}$ Khakass Technical Institute, Siberian Federal University \\ Abakan, Russian Federation
}

\begin{abstract}
A theoretical and experimental verification of a simple hypothesis was carried out in this study to determine if features of the anatomical structure of coniferous annual rings (in a case study of pine trees from moisture-deficient growth conditions in the steppe zone) quantified in tracheidograms of annual rings can be used to reconstruct the kinetics of seasonal growth. During two sharply different growth seasons, sampling was performed periodically, and seasonal growth of tree rings was measured where the forming annual ring was separated into zones (cambium, extension zone, zone of cell wall thickening, zone of mature tracheids). Based on these data and total tracheidograms, a simple scheme for converting the variability of the radial cell sizes into cumulative and differential cell production curves was proposed. Statistical analysis revealed both correspondence and discrepancies between theoretical and experimental data, showed the prospects of the proposed approach, and suggested the need for longer seasonal observations.
\end{abstract}

Keywords: steppe zone, Scots pine, seasonal growth, tracheidograms, radial cell size, modeling.

Acknowledgments. The reported study was funded by RFBR according to the research project No. 19-04-00274.

(C) Siberian Federal University. All rights reserved

This work is licensed under a Creative Commons Attribution-NonCommercial 4.0 International License (CC BY-NC 4.0).

* Corresponding author E-mail address: zharkov_12_mihail@mail.ru ORCID: 0000-0003-0522-1892 (Zharkov M.); 0000-0002-8475-7304 (Belokopytova L.); 0000-0002-2415-8019 (Fonti M.); 0000-0002-1355-4307 (Babushkina E.); 0000-0001-9168-1152 (Vaganov E.) 
Citation: Zharkov M.S., Belokopytova L. V., Fonti M. V., Babushkina E. A., Vaganov E. A. What quantitative anatomy can provide for kinetics of xylogenesis: analysis of cell radial diameters. J. Sib. Fed. Univ. Biol., 2021, 14(1), 84-96. DOI: 10.17516/19971389-0342

\title{
Что может дать количественная анатомия
}

Для кинетики ксилогенеза:

анализ радиальных размеров клеток

М.С. Жарков ${ }^{a}$, Л. В. Белокопытова М. В. Фонти ${ }^{a}$, Е.А. Бабушкина ${ }^{\sigma}$, Е. А. Ваганов ${ }^{a}$

${ }^{a}$ Сибирский федеральный университет

Российская Федераиия, Красноярск

${ }^{6}$ Хакасский технический институт

Сибирский федеральный университет

Российская Федераџия, Абакан

\begin{abstract}
Аннотация. В работе проведена теоретико-экспериментальная проверка простой гипотезы: могут ли особенности анатомического строения годичных колец хвойных (на примере деревьев сосны из дефицитных по увлажнению условий роста в степной зоне), зафиксированные количественно в трахеидограммах годичных колец, быть использованы для реконструкции кинетики сезонного роста. На примере двух резко различающихся сезонов роста, в течение которых с отбором периодических проб измерялся сезонный рост годичных колец с разделением формирующегося годичного кольца на зоны (камбий, зона растяжения, зона утолщения клеточной стенки, зона зрелых трахеид), и итоговых трахеидограмм предложена простая схема пересчета изменчивости радиальных размеров клеток в кумулятивную и дифференциальную кривые продукции клеток. Статистический анализ выявил как соответствия, так и расхождения между теоретическими и экспериментальными данными, представил перспективы предлагаемого подхода и указал на необходимость более длительных сезонных наблюдений.
\end{abstract}

Ключевые слова: степная зона, сосна обыкновенная, сезонный рост, трахеидограммы, радиальный размер клетки, моделирование.

Благодарности. Исследование выполнено при финансовой поддержке РФФИ в рамках научного проекта РФФИ № 19-04-00274.

Цитирование: Жарков, М.С. Что может дать количественная анатомия для кинетики ксилогенеза: анализ радиальных размеров клеток / М. С. Жарков, Л. В. Белокопытова, М. В. Фонти, Е. А. Бабушкина, Е. А. Ваганов // Журн. Сиб. федер. ун-та. Биология, 2021. 14(1). С. 84-96. DOI: 10.17516/1997-1389-0342 


\section{Введение}

Сезонное развитие хвойного древесного растения четко отражается в структуре формирующегося годичного кольца: крупные тонкостенные клетки ранней древесины, обеспечивающие восходящие потоки воды и минеральных веществ в период активного роста и формирования фотосинтетического аппарата растения, постепенно сменяются толстостенными клетками меньших радиальных размеров во второй половине сезона (Яценко-Хмелевский, 1954; Чавчавадзе, 1979; Ваганов и др.,1985; Vaganov et al., 2006; Cuny et al., 2014; Carteni et al., 2018). Начальный интервал сезона сопряжен и с большей активностью камбия, что отражается в увеличении размеров камбиальной зоны и зоны, занятой растягивающимися клетками (Deslauriers et al., 2003; Rossi et al., 2007; Huang et al., 2014). В течение сезона роста фиксируется постепенный переход клеток из камбия в зону растяжения, затем в зону одревеснения клеточной стенки, что в итоге заканчивается потерей клетки протоплазмы и включением ее в формирующуюся водопроводящую систему - ксилему (Гамалей, 1972; Larson, 1994; Vaganov et al., 2006; Olano et al., 2014; Prendin et al., 2017). Особенности кинетики каждого этапа в конечном итоге отражаются в окончательных анатомических характеристиках трахеид: радиальном размере и толщине клеточной стенки (Ваганов и др., 1985; Camarero et al., 2010; Martin-Benito et al., 2013; Cuny et al., 2014; Rossi et al., 2014). Резонен вопрос, можно ли, измеряя анатомические характеристики сформированных трахеид, получить информацию о некоторых важных кинетических показателях сезонного формирования ксилемы. В данной работе мы предприняли попытку проверить одну простую гипотезу - могут ли радиальные размеры трахеид быть количественными показателями скорости продукции клеток в течение сезона.

\section{Материалы и методы}

Объекты исследования

Объектами исследования были деревья сосны (Pinus sylvestris L.), произрастающие в разновозрастном сосновом бору Минусинской котловины (5339' с. ш., 91³5' в. д., 320 м над у. м.). Климат района исследований резкоконтинентальный, со среднегодовой температурой в $1,2{ }^{\circ} \mathrm{C}$ и количеством осадков около 340 мм/год (по многолетним данным метеостанции «Минусинск» (WMO ID29866, 5341' с. ш., 9140' в. д., 250 м над у. м.; https://meteo. ru; Fonti, Babushkina, 2016; Belokopytova et al., 2019; Tychkov et al., 2019). Тип леса - мезоксерофильный бор, напочвенный покров лишайниковый, осоково-злаково-разнотравный. Сомкнутость - 0,6, средний диаметр - 38 см, высота - 21 м. Проективное покрытие подлеска (карагана, кизильник, шиповник) - 30 \%, проективное покрытие травяно-кустрничкового яруса (касатик русский, тимофеевка степная, мятлик луговой, прострел желтеющий, василисник малый) - 40-50 \%. Для измерений сезонного роста в 2013 и в 2014 гг. были отобраны по 5 деревьев в древостое возрастом 35-40 лет.

\section{Сезонные измерения}

В течение сезонов 2013 и 2014 гг. (с начала апреля до середины сентября) у выбранных деревьев отбирали керны древесины длиной около 1 см (с включением 2-3 годичных колец предыдущих лет роста) по окружности со смещением с периодичностью 1 раз в неделю (Rossi et al., 2006; Ziaco, Biondi, 2016; Fonti et al., 2020). Образцы фиксировали (глицерин-спирт-вода (Фурст, 1979)), затем в лабораторных условиях с них на санном микротоме Thermo Scientific Microm HМ 450 были получены тонкие (15 мкм) поперечные срезы, которые окрашивали раствором астра-голубого (2 \%) и сафранина (1 \%) для контрастного окрашивания лигнифицированных и нелигнифицированных клеток. 
Число клеток в различных зонах формирующихся колец измеряли с помощью системы анализа изображений (Carl Zeiss Jena, Germany) и программного пакета AxioVision SE Rel. 4.9.1. В каждом годичном кольце измеряли 5 рядов клеток, затем значения усредняли, при этом выделяли зоны: камбиальная, растяжения клеток, зона первичной лигнификации и зона зрелых трахеид.

\section{Измерения трахеидограмм}

На последних сезонных образцах (середина сентября) были произведены измерения характеристик трахеид полностью сформированных годичных колец 2013 и 2014 гг. Анатомические клеточные характеристики древесины деревьев были измерены на препаратах поперечных срезов древесины при помощи системы анализа изображений, состоящей из биологического микроскопа Ахіо Imager D1, USB-видеокамеры АхіоCAM Mrc5 и компьютера с установленным программным обеспечением Lineyka и ProcessorKR, созданными д. б. н., проф. П.П. Силкиным (Силкин, $2009,2010)$. Эта система позволяет измерять размеры клеток и их частей (Munro et al., 1996). В каждом кольце для измерения выбирали 5 рядов клеток с наибольшей площадью поперечного сечения (Babushkina et al., 2019). Программа Lineyka (рис. 1) может работать с любым стандартным графическим файлом, содержащим изображение поперечного среза годичного кольца. Измерение расстояния основано на подсчете количества пикселей между концами измеряемого отрезка с последующим умножением их количества на коэффициент масштабирования (определяемый для каждого режима увеличения микроскопа по фотографии микрометра), т. е. размер пикселя изображения. Lineyka имеет два режима измерения - ручной и полуавтоматический. В процессе измерения оба режима можно чередовать в любой последовательности. В режиме ручного измерения оператор вдоль радиального ряда клеток курсором компьютерной мыши задает концы последовательных отрезков, длину которых необходимо измерить (радиального диаметра люмена LD и толщины двойной клеточной стенки 2CWT). В полуавтоматическом режиме курсором задается целиком линия через весь радиальный ряд клеток, и по интенсивности цвета изображения вдоль этой линии распознаются границы люмена и стенки. Далее в программе ProcessorKR осуществляется первичная обработка измерений: на основе размера люмена и толщины двойной клеточной стенки производится расчет радиального размера $(\mathrm{D}=\mathrm{LD}+2 \mathrm{CWT})$ и одинарной толщины стенки для каждой клетки, затем - нормирование каждого ряда измерений к среднему количеству клеток в измеренных радиальных рядах по каждому кольцу либо к фиксированному количеству клеток. Поскольку каждое годичное кольцо у экспериментальных деревьев в исследованные годы насчитывало разное количество клеток, то измеренные трахеидограммы (изменчивость радиальных размеров и толщины клеточной стенки в отдельных рядах от внутренней границы кольца к внешней) стандартизовались к среднему числу клеток $\mathrm{N}$, измеренных для 5 деревьев (Vaganov, 1990; Belokopytova et al., 2019), т. е. к 32 и 50 клеткам соответственно.

\section{Аналитическое преобразование \\ радиальных размеров \\ в сезонную динамику роста}

Исходная гипотеза состоит в том, что относительная скорость продукции (т. е. скорость выхода клетки из камбия в зону растяжения) есть пропорциональная функция от радиального размера клетки. При этом основное допущение: каждая последовательная клетка в измеряемой трахеидограмме появляется в зоне растяжения после предшествующей с опреде- 


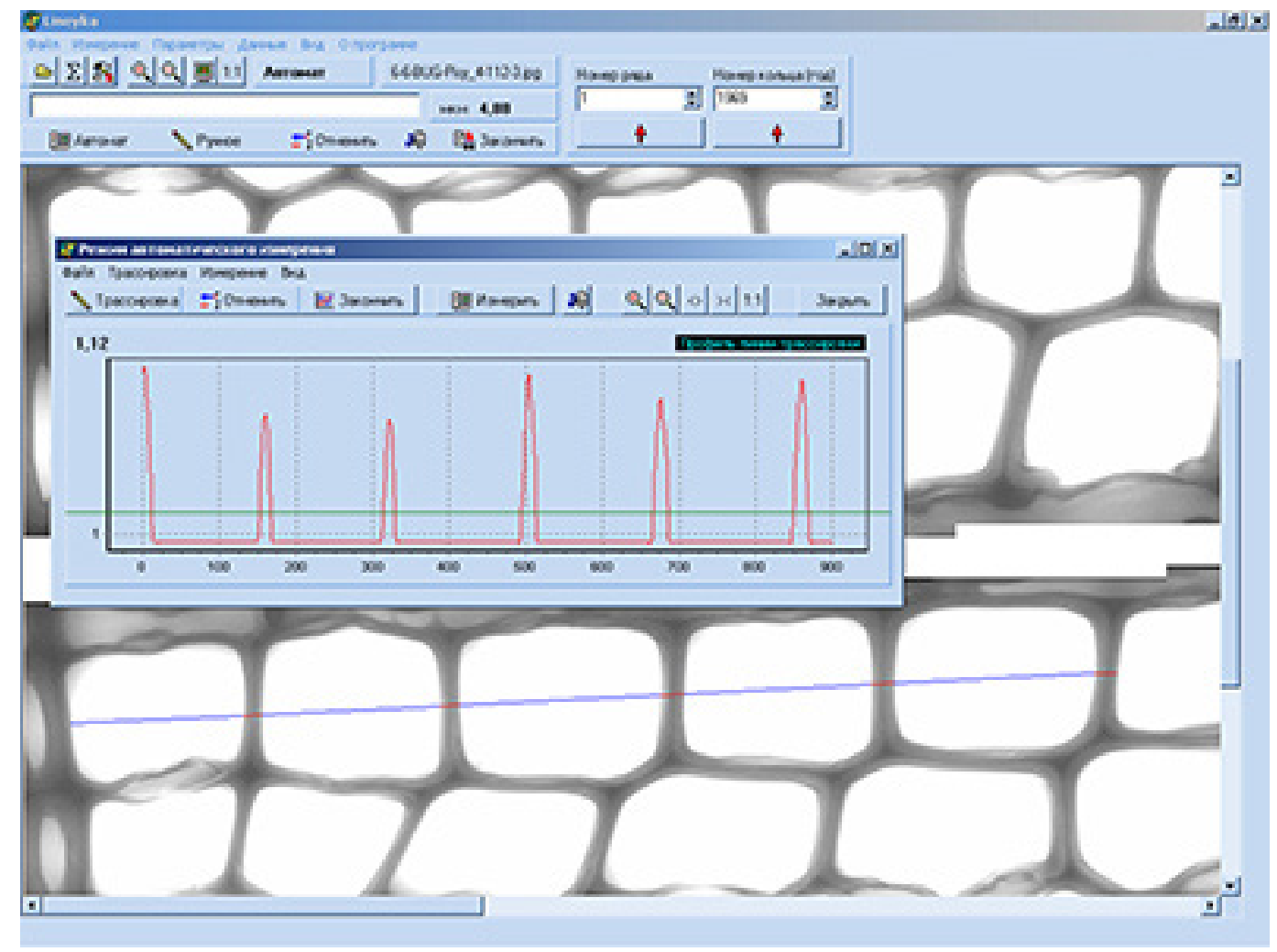

Рис. 1. Автоматизированное измерение люмена и двойной клеточной стенки (описание в тексте)

Fig. 1. Automated measurement of lumen and double cell wall (description in the text)

ленным временным интервалом. Аналитически гипотеза выражается как

$$
V_{i}-V_{0}=\alpha^{*}\left(D_{i}-7\right)
$$

где $\mathrm{V}_{\mathrm{i}}$ - скорость продукции і-той клетки (клеток в сутки); $\mathrm{V}_{0}$ - скорость деления камбиальной инициали (деление происходит примерно каждые 25 сут, т. е. $\mathrm{V}_{0}=0.08$ клеток в сутки, по оценкам, представленным в ранее опубликованных работах: Иванов, 1987; Гриф, Иванов, 1995; Larson, 1994; Vaganov et al., 2006); $\mathrm{D}_{\mathrm{i}}$ - радиальный размер і-той клетки (мкм); 7 мкм - минимальный размер клетки, наблюдаемый при ее переходе в зону растяжения (принят по среднему радиальному размеру клеток камбиальной зоны в исследуемых образцах); $\alpha$ - коэффициент пропорциональности.
Гипотеза о пропорциональности радиальных размеров клеток и скорости их продукции при рассмотрении трахеидограммы приводит к следующей зависимости:

$$
t_{i}=\gamma *\left(1 / V_{i}\right)
$$

где $\mathrm{t}_{\mathrm{i}}$ - промежуток времени между продукцией камбием $\mathrm{D}_{\mathrm{i}-1}$ и $\mathrm{D}_{\mathrm{i}}$-той клеток; $\gamma$ - коэффициент пропорциональности. Сумма $\mathrm{t}_{\mathrm{i}}$ соответствует всему периоду сезонной продукции клеток, т. е.

$$
T=\gamma * \sum t_{i}=\gamma * \sum\left(1 / V_{i}\right) \text { для } i=1 \ldots \mathrm{N},
$$

где Т - период продукции клеток, суммарная длительность генерации трахеид от первой до последней клетки в трахеидограмме. 
Поэтому при определенной выше зависимости между радиальным размером клеток и скоростью продукции клеток для расчета промежутков времени между продукцией (переходу из камбия в зону растяжения) каждой последовательной клетки в трахеидограмме нужно также знать период продукции Т. Практически можно оценить Т двумя способами: 1) по динамике температуры (выше предельного значения, например $5{ }^{\circ} \mathrm{C}$ (при отсутствии данных сезонных измерений кинетики)); 2) подбором, максимизируя корреляцию между расчетной кривой сезонного роста и измеренной (в случае наличия сезонных наблюдений). Таким образом, зная измерения радиальных размеров клеток по трахеидограмме и оценку длительности продукции клеток в сезоне (T), можно рассчитать время появления каждой последовательной клетки в зоне растяжения (продукция камбиальной зоной) и восстановить кинетику продукции клеток в течение сезона.

\section{Результаты}

Сезонные особенности

температуры и осадков

В 2013 г. устойчивое повышение температуры выше $5{ }^{\circ} \mathrm{C}$ отмечается с 27 апреля (DOY=117), достигает максимума в первую половину июля и снижается ниже $5{ }^{\circ} \mathrm{C} \mathrm{c} 9$ сентября (DOY=252). Осадки, что типично для данного региона с дефицитом увлажнения, неравномерны и недостаточны в первой половине сезона, особенно в июне и первой половине июля. В 2014 г. в начале сезона температура поднималась медленно, колеблясь около $5{ }^{\circ} \mathrm{C}$ в течение двух месяцев с 19 марта (DOI=79) по 19 мая $(\mathrm{DOY}=140)$. Заметный и значительный подъем температуры отметился со второй половины июня при достаточно равномерном распределении осадков во времени. Снижение температуры ниже $5{ }^{\circ} \mathrm{C}$ произошло с 23 сентября (DOY=267).
Кинетика ксилогенеза и трахеидограммы

На рис. 2 представлены усредненные трахеидограммы (a, б), используемые для кинетических расчетов, а также экспериментальные и расчетные кинетические кривые: динамика численности клеток в камбиальной зоне (д, е) и зоне растяжения клеток (ж, з), кривые нарастания общей численности клеток в формирующемся годичном кольце (и, к) и скорость продукции клеток (л, м), измеренные и рассчитанные по вышеописанной схеме. Для расчета общий период сезона продукции (T) был на данном этапе оценен из экспериментальных кинетических кривых и равнялся 160 сут для 2013 и 165 сут - для 2014 г. Оба года существенно различны как по кинетике, так и по трахеидограммам. В верхней части рис. 2 приведены трахеидограммы (изменчивость радиальных размеров клеток и толщины клеточной стенки), нормированные к среднему числу клеток в годичных кольцах экспериментальных деревьев на момент завершения сезона роста (к 20 сентября). 2013 г. характеризуется четко выраженной флуктуацией плотности древесины (intra-annual density fluctuation, IADF) (Camarero et al., 2010; Popkova et al., 2018), образованной значительным уменьшением радиальных размеров нескольких клеток во второй половине ранней древесины, 2014 г. - типичный год с постепенным уменьшением размеров клеток от ранней древесины к поздней по мере продукции новых клеток в сезоне. При этом относительная численность клеток с утолщенными стенками также существенно различается: 62 и $33 \%$ для 2013 и 2014 гг. соответственно. Интересно, что первые клетки переходной зоны (увеличение в утолщении клеточной стенки) в 2013 г. занимают 12-13 позиции в нормированной трахеидограмме и произведены они в конце июня. В 2014 г. первые клетки переходной зоны занимают 35-36 позиции в нормированной трахеидограмме и по кинетическим данным про- 
2013 r.
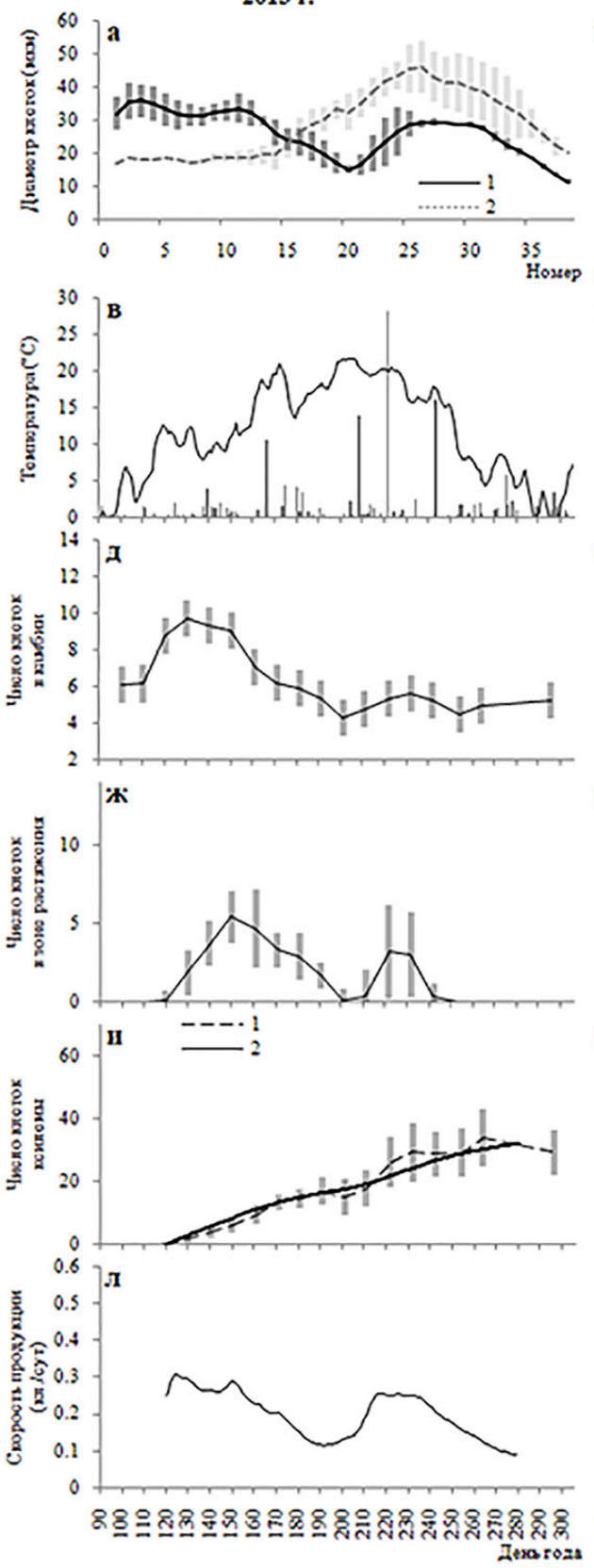

2014 r.

б
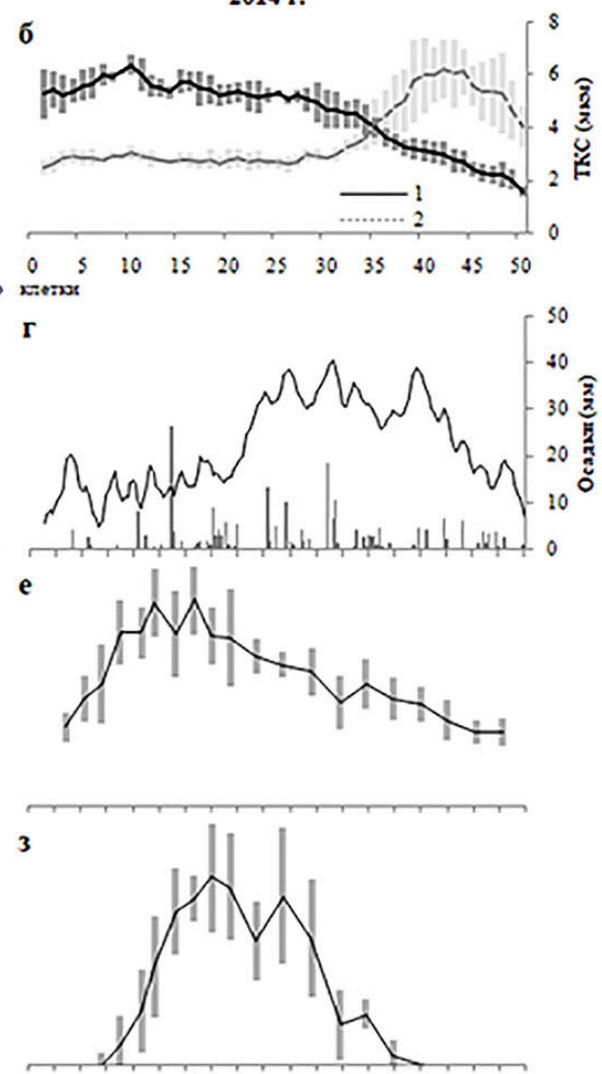

к $\quad---1$

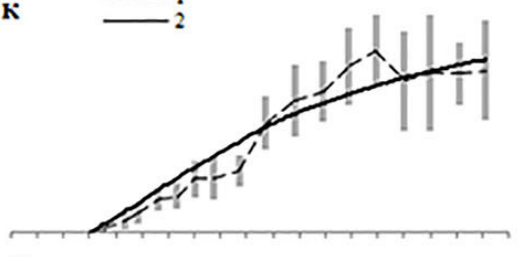

II

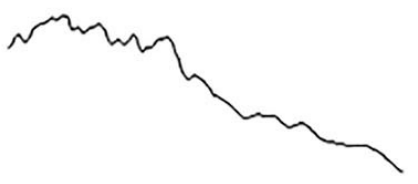

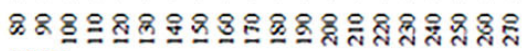
(DOY)

Рис. 2. Трахедограммы (1 - радиальный размер клеток, 2 - толщина клеточной стенки) (a, б), динамика температуры и осадков (в, г) и измеренные кинетические характеристики (число клеток в камбии $(д$, e), число клеток в зоне растяжения (ж, 3)) годичных колец сосны в 2013 и 2014 гг. В нижней части рисунка - сопоставление измеренных (1) и расчетных (2) кривых нарастания общего числа клеток ксилемы формирующегося годичного кольца (и, к), а также расчетных кривых скорости продукции клеток (л, м) из трахеидограмм за эти же годы

Fig. 2. Tracheidograms (1 - radial cell size, 2 - cell wall thickness) (a, b), dynamics of temperature and precipitation (c, d) and measured kinetic characteristics (number of cells in cambium (e, f), number of cells in the extension zone $(\mathrm{g}, \mathrm{h})$ ) of pine tree rings in 2013 and 2014. In the lower part of the figure, there is a comparison of the measured (1) and calculated (2) curves of the increase in the total number of cells in the xylem of forming ring (i,j), as well as the calculated curves of the cell production rate $(\mathrm{k}, 1)$ from tracheidograms in the same years 
дуцируются (появляются в зоне растяжения) также в конце июня. Если по абсциссе у трахеидограмм изменяется число клеток (от первой до последней в измеренных радиальных рядах), то все нижерасположенные графики имеют по абсциссе временную шкалу (в днях года от 1 января - DOY).

Основное различие в климатических условиях сопоставляемых лет - наличие длительного (около 1 месяца) умеренного подъема температуры до начала июня в 2014 г. (рис. 26, 2). Именно в этот период численность клеток в камбиальной зоне в годичных кольцах сосны достигает максимума, что отражается и в большей численности клеток в зоне растяжения и окончательно в большей общей продукции клеток за сезон (в среднем 50 клеток). При этом резкое повышение температуры в середине июня (рис. 22) отзывается максимумом клеток в зоне растяжения и ускорением прироста общей численности клеток в трех зонах (рис. 23, к). В 2013 г. камбий среагировал на первый подъем температуры (майский), но невысокой численностью, затем численность клеток как в камбии, так и в зоне растяжения уменьшалась в течение июня-первой декады июля, второй «пик» активности проявился в июле-августе (рис. $2 \partial$, ж). Можно полагать, что в этот сезон второй пик активности камбия, ответственный за появление «ложного кольца», связан с сочетанием высоких температур и серии интенсивных дождей в первой половине июля, что обеспечило хорошие условия для роста годичного кольца.

Расчетные кривые кинетики сезонного роста по радиальным размерам трахеид приведены на рис. $2 u-м$ в двух вариантах: как кумулятивные кривые общего количества клеток в формирующемся кольце (суммарное число клеток в зоне растяжения, утолщения клеточной стенки и зрелых трахеид), которые сравниваются с экспериментальными кривыми, и дифференциально как скорость продукции клеток. На рис. 3 приведены графики корреляции между расчетными кумулятивными кривыми роста, а также между расчетными кривыми скорости продукции и численностью клеток в камбиальной зоне и зоне растяжения. Корреляция кумулятивных расчетных и экспериментальных кривых количества клеток (рис. $3 a$ ) очень высокая (R>0,9), но она определяется во многом сезонным трендом в увеличении продукции клеток в кольце. При этом согласие в 2013 г. (год с ложным кольцом) лучше, чем в 2014 г. В 2014 г. расчетная кумулятивная кривая заметно превышает экспериментальную в первой половине сезона и хорошо согласуется с таковой во второй половине сезона. Корреляция расчетных скоростей продукции клеток с численностью клеток в камбии и зоне растяжения (рис. 36, в) значима, но заметно меньше $(0,53-0,72)$ и разброс значений достаточно велик. При этом можно отметить существенное расхождение в аппроксимирующих моделях регрессии для численности клеток в камбии (рис. 3б) между годами и лучшее схождение в моделях для двух лет для численности клеток в зоне растяжения (рис. 36). Но четко прослеживается то, что численность клеток в зоне растяжения больше при больших значениях расчетной скорости продукции клеток. Это справедливо и для более узких (меньше общая продукция клеток) колец 2013 г., и для более широких колец, сформированных в 2014 г.

\section{Обсуждение}

Результаты проверки исходной гипотезы, а именно можно ли по трахеидограмме годичного кольца сделать оценки кинетики сезонного роста, на примере двух сезонов для деревьев сосны из степных условий показали следующее. Пересчет радиальных размеров клеток в кинетику продукции клеток (кумулятивную и скорость продукции) достаточно адекват- 

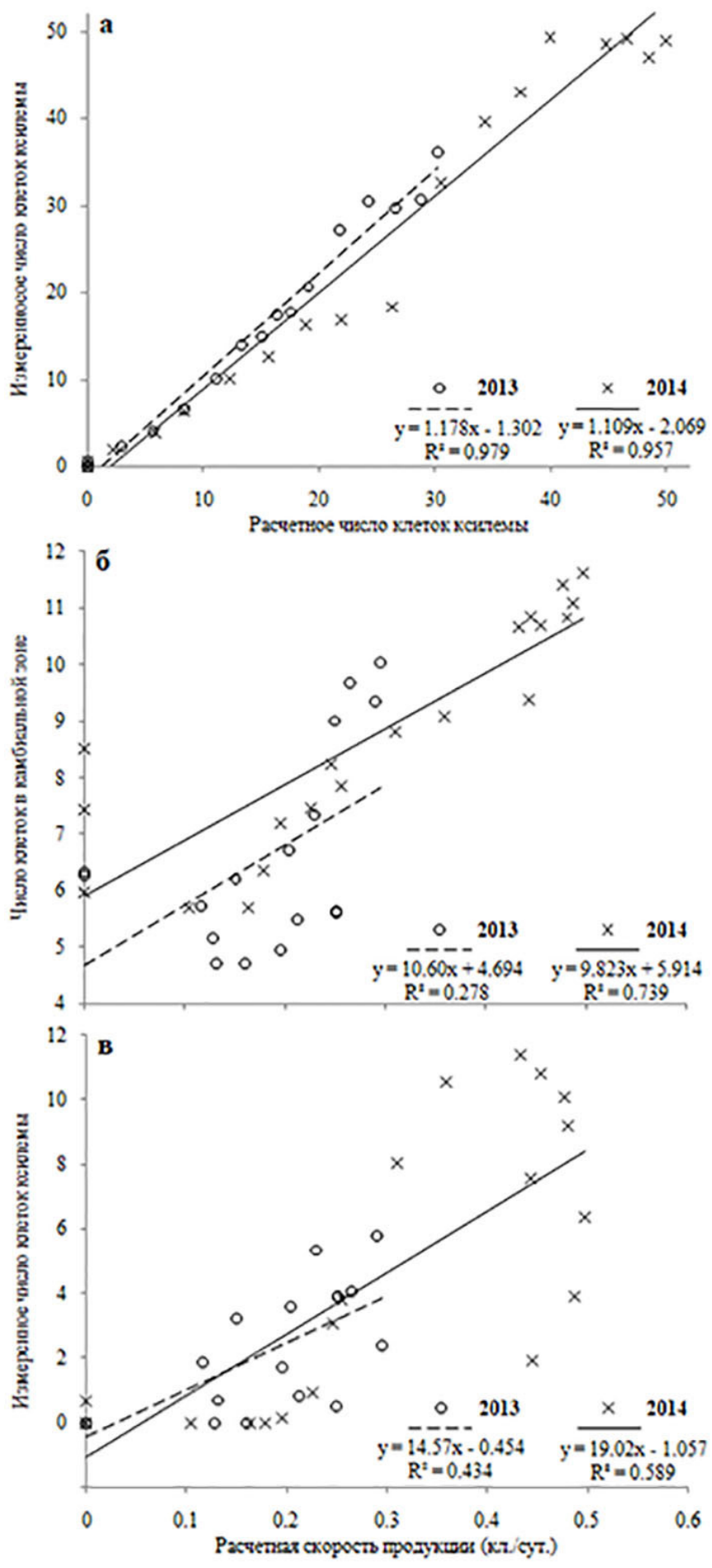

Рис. 3. Корреляции и линейные регрессии расчетных и измеренных характеристик в 2013 (кружки) и 2014 гг. (крестики): измеренное и расчетное общее число клеток в формирующемся кольце (а), расчетная скорость продукции клеток и измеренное число клеток в камбии (б) и в зоне растяжения (в)

Fig. 3. Correlations and linear regressions of calculated and measured characteristics in 2013 (circles) and 2014 (crosses): measured and calculated total number of cells in the forming ring (a), calculated cell production rate and measured number of cells in cambium (b) and in the extension zone (c) 
но сработал в сезоне 2013 г., в сезоне с особой структурой годичного кольца (внутрисезонное формирование «ложного» кольца), но показал существенное расхождение с экспериментальными величинами для более «нормального» года роста (2014 г.), в течение которого сформировалась значительная доля клеток ранней древесины, а толстостенные клетки переходной и поздней зоны составили 33 \% от общего количества клеток в кольце. Наиболее заметное расхождение между расчетными скоростями продукции и численностью клеток в зоне растяжения (оценка продуктивности клеток камбием) (Rathgeber, 2017; Castagneri et al., 2017) приходится на начальный этап сезона роста. В этот период сезона 2014 г. расчетная скорость продукции достигает максимальных значений, но если в камбиальной зоне число клеток тоже близко к максимуму, то клеток в зоне растяжения заметно меньше. Ясно понимая, что численность клеток в зоне растяжения косвенный показатель абсолютной продукции клеток камбием (определяется как скоростью продукции клеток камбием, так и скоростью и длительностью растяжения клеток) (Cuny et al., 2014; Carrer et al., 2017; Rathgeber, 2017), авторы ряда детальных работ убедительно демонстрируют, что длительность растяжения трахеиды вносит существенно больший вклад в ее окончательный размер, чем его скорость (Cuny et al., 2014; Cuny, Rathgeber, 2016), поэтому сопоставление расчетной скорости продукции клеток и их численности в зоне растяжения вполне оправданно.

Численность клеток в камбии, пожалуй, показатель, имеющий наибольшую относительную ошибку в измерениях, для оценки которого было использовано несколько цитологических методов (Larson, 1994). Более того, он существенно варьирует у разных деревьев с разной энергией роста, что вносит еще большую вариабельность при оценке данного кинетического показателя (Wodziski, 1971; Deslauriers et al., 2003). В сезоне 2013 г. мы наблюдаем достаточно активный переход первых клеток из камбия в зону растяжения, однако в сезоне 2014 г. переход из камбия в зону растяжения существенно замедлился вследствие невысокой температуры в этот период (в среднем около $10{ }^{\circ} \mathrm{C}$ до середины июня). Значение раннелетней температуры для кинетики продукции камбием клеток ранней древесины подтверждаются как прямыми данными фенологии камбия, так и данными моделирования сезонного роста (Vaganov et al., 2006; Evans et al., 2006; Yang et al., 2017; Du et al., 2020; Tychkov et al., 2019). Тем не менее радиальные размеры клеток, продуцируемых в это время в сезоне 2014 г., оказались в итоге больше, чем в аналогичный период в годичных кольцах 2013 г. Это и обусловило значительное расхождение между расчетными и экспериментальными кинетическими кривыми. С другой стороны, если рассматривать численность клеток в камбии, то здесь в сезоне 2014 г. отмечается значимая корреляция с расчетной скоростью продукции клеток (рис. 3б). Численность клеток камбия также связана со скоростью роста (продукции) клеток в самом камбии, и в значительном числе работ показано, что общая продукция клеток в годичном кольце прямо пропорциональна числу клеток в камбии в активный период роста (Gregory, Wilson, 1968; Свидерская, 1999; Vaganov et al., 2006; Drew, Downes, 2015). Поэтому если умеренная температура в начале сезона 2014 г. могла сдерживать быстрый переход клеток в зону растяжения, то повышенная численность клеток в камбии в начале сезона 2014 г. вполне соответствует ускоренному росту клеток в самой камбиальной зоне. То есть использованное нами определение продукции клеток как их суммарного числа в зонах растяжения, утолщения клеточной стенки и зрелых трахеид должно быть скорректировано с уче- 
том скорости делений клеток в самой камбиальной зоне. Это может трансформировать рассматриваемую нами гипотезу, но потребует более длительных наблюдений за сезонной активностью камбия и дифференцировкой трахеид. Полагая данную работу достаточно пионерной, мы уверены, что корректировка алгоритма пересчета данных трахеидограмм в кинетические характеристики сезонного формирования годичного кольца имеет хорошую перспективу, поскольку в таком случае в руках исследователя может оказаться уникальный материал, который позволит не только использовать обычные статистические методы для сопоставления анатомических характеристик и климатических и иных факторов, но и более детально рассматривать влияние климатических факторов на отдельные фазы дифференцировки клеток ксилемы в процессе формирования годичного кольца.

\section{Список литературы / References}

Ваганов Е. А., Шашкин А.В., Свидерская И. В., Высоцкая Л.Г. (1985) Гистометрический анализ роста древесных растений. Новосибирск, 100 с. [Vaganov E. A., Shashkin A. V., Sviderskaya I. V., Vysotskaya L. G. (1985) Histometric analysis of the growth of woody plants. Novosibirsk, 100 p. (in Russian)]

Гамалей Ю. В. (1972) Цитологические основы дифференцировки ксилемы. Ленинград, 208 c. [Gamalei U. V. (1972) Cytological basis of xylem differentiation. Leningrad, 208 p. (in Russian)]

Гриф В. Г., Иванов В. Б. (1995) Временные параметры митотического цикла у цветковых растений. Цитология, 37 (8): 723-743 [Grif V. G., Ivanov B. V. (1995) Temporal parameters of the mitotic cycle in flowering plants. Cytology, 37 (8): 723-743 (in Russian)]

Иванов В.Б. (1987) Пролиферация клеток в растениях. Итоги науки и техники. Цитология, 5: 219 [Ivanov V. B. (1987) Cell proliferation in plants. Results of science and technology. Cytology, 5: 219 (in Russian)]

Свидерская И.В. (1999) Гистометрический анализ закономерностей сезонного формирования древесины хвойнылх. Автореф. дис. канд. биол. наук. Красноярск, 22 с. [Sviderskaya I. V. (1999) A histometric analysis of the patterns of seasonal formation of coniferous wood. Abstract of the diss. of the cand. of biol. sciences. Krasnoyarsk, 22 p. (in Russian)]

Силкин П.П. (2009) Многопараметрический анализ структуры годичных колеи в дендроэкологических исследованиях. Автореф. дис. д-ра биол. наук. Красноярск, 34 с. [Silkin P. P. (2009) Multiparameter analysis of the structure of tree rings in dendroecological studies. Abstract of the diss. doct. biol. sciences. Krasnoyarsk, 34 p. (in Russian)]

Силкин П.П. (2010) Методы многопараметрического анализа структуры годичных колец хвойных. Красноярск, 335 с. [Silkin P.P. (2010) Methods of multi-parameter analysis of the structure of coniferous annual rings. Krasnoyarsk, 335 p. (in Russian)]

Фурст Г.Г. (1979) Методы анатомо-гистохимического исследования растительных тканей. Москва, 156 с. [Furst G. G. (1979) Methods of anatomical and histochemical studies of plant tissues. Moscow, 156 p. (in Russian)]

Чавчавадзе Е. С. (1979) Древесина хвойных. Ленинград, 192 с. [Chavchavadze E. S. (1979) Coniferous wood. Leningrad, 192 p. (in Russian)]

Яценко-Хмелевский А.А. (1954) Основы и методы анатомического исследования древесины. Москва, 338 с. [Yatsenko-Khmelevsky A.A. (1954) Fundamentals and methods of anatomical research of wood. Moscow, 338 p. (in Russian)] 
Babushkina E. A., Belokopytova L. V., Zhirnova D. F., Vaganov E. A. (2019) Siberian spruce tree ring anatomy: imprint of development processes and their high-temporal environmental regulation. Dendrochronologia, 53: 114-124

Belokopytova L. V., Babushkina E. A., Zhirnova D. F., Panyushkina I.P., Vaganov E. A. (2019) Pine and larch tracheids capture seasonal variations of climatic signal at moisture-limited sites. Trees, 33 (1): 227-242

Camarero J. J., Olano J.M., Parras A. (2010) Plastic bimodal xylogenesis in conifers from continental Mediterranean climates. New Phytologist, 185 (2): 471-480

Carrer M., Castagneri D., Prendin A. L., Petit G., von Arx G. (2017) Retrospective analysis of wood anatomical traits reveals a recent extension in tree cambial activity in two high-elevation conifers. Frontiers in Plant Science, 8: 737

Carteni F., Deslauriers A., Rossi S., Morin H., De Micco V., Mazzoleni S., Giannino F. (2018) The physiological mechanisms behind the earlywood-to-latewood transition: a process-based modeling approach. Frontiers in Plant Science, 9: 1053

Castagneri D., Fonti P., von Arx G., Carrer M. (2017) How does climate influence xylem morphogenesis over the growing season? Insights from long-term intra-ring anatomy in Picea abies. Annals of Botany, 119 (6): 1011-1020

Cuny H.E., Rathgeber C.B.K., Frank D., Fonti P., Fournier M. (2014) Kinetics of tracheid development explain conifer tree-ring structure. New Phytologist, 203 (4): 1231-1241

Cuny H.E., Rathgeber C.B.K. (2016) Xylogenesis: Coniferous trees of temperate forests are listening to the climate tale during the growing season but only remember the last words! Plant Physiology, 171 (1): $306-317$

Drew D. M., Downes G. (2015) A model of stem growth and wood formation in Pinus radiata. Trees, 29 (5): 1395-1413

Deslauriers A., Morin H., Begin Y. (2003) Cellular phenology of annual ring formation of Abies balsamea in Quebec boreal forest (Canada). Canadian Journal of Forest Research, 33 (2): 190-200

Deslauriers A., Morin H. (2005) Intra-annual tracheid production in balsam fir stems and the effect of meteorological variables. Trees, 19 (4): 402-408

Du J., Li K., He Z., Chen L., Lin P., Zhu X. (2020) Daily minimum temperature and precipitation control on spring phenology in arid-mountain ecosystems in China. International Journal of Climatology, 40 (5): $2568-2579$

Evans M.N., Reichert B. K., Kaplan A., Anchukaitis K. J., Vaganov E. A., Hughes M. K., Cane M. A. (2006) A forward modeling approach to paleoclimatic interpretation of tree-ring data. Journal of Geophysical Research-Biogeosciences, 111 (G3): G03008

Fonti M. V., Babushkina E. A., Zhirnova D. F., Vaganov E. A. (2020) Xylogenesis of Scots pine in an uneven-aged stand of the Minusinsk Depression (Southern Siberia). Journal of Siberian Federal University. Biology, 13(2): 197-207

Fonti P., Babushkina E.A. (2016) Tracheid anatomical responses to climate in a forest-steppe in Southern Siberia. Dendrochronologia, 39: 32-41

Gregory R.A., Wilson B.F. (1968) A comparison of cambial activity of white spruce in Alaska and New England. Canadian Journal of Botany, 46(6): 733-734

Huang J. G., Deslauriers A., Rossi S. (2014) Xylem formation can be modelled statistically as a function of primary growth and cambium activity. New Phytologist, 203 (3): 831-841 
Larson P. R. (1994) The vascular cambium: Development and structure. Berlin, Heidelberg, Springer-Verlag, $725 \mathrm{p}$.

Martin-Benito D., Beeckman H., Canellas I. (2013) Influence of drought on tree rings and tracheid features of Pinus nigra and Pinus sylvestris in a mesic Mediterranean forest. European Journal of Forest Research, 132 (1): 33-45

Munro M. A.R., Brown P. M., Hughes M. K., Garcia E. M.R. (1996) Image analysis of tracheid dimensions for dendrochronological use. Tree rings, environment and humanity. Proceedings of the International Conference, Tucson, Arizona, 17-21 May 1994. Dean J. S., Meko D. M., Swetnam T. W. (Eds.) Radiocarbon, Tucson, AZ, USA, p. 843-852

Olano J. M., Linares J. C., García-Cervigón A.I., Arzac A., Delgado A., Rozas V. (2014) Droughtinduced increase in water-use efficiency reduces secondary tree growth and tracheid wall thickness in a Mediterranean conifer. Oecologia, 176 (1): 273-283

Popkova M.I., Vaganov E. A., Shishov V. V., Babushkina S. A., Rossi S., Fonti M. V., Fonti P. (2018) Modeled tracheidograms disclose drought influence on Pinus sylvestris tree-ring structure from Siberian forest-steppe. Frontiers in Plant Science, 9: 1144

Prendin A.L., Petit G., Carrer M., Fonti P., Björklund J., von Arx G. (2017) New research perspectives from a novel approach to quantify tracheid wall thickness. Tree Physiology, 37 (7): 976-983

Rathgeber C.B.K. (2017) Conifer tree-ring density inter-annual variability - anatomical, physiological and environmental determinants. New Phytologist, 216 (3): 621-625

Rossi S., Deslauriers A., Anfodillo T. (2006) Assessment of cambial activity and xylogenesis by microsampling tree species: an example at the alpine timberline. IAWA Journal, 27 (4): 383-394

Rossi S., Deslauriers A., Anfodillo T., Carraro V. (2007) Evidence of threshold temperatures for xylogenesis in conifers at high altitudes. Oecologia, 152 (1): 1-12

Rossi S., Girard M.J., Morin H. (2014) Lengthening of the duration of xylogenesis engenders disproportionate increases in xylem production. Global Change Biology, 20 (7): 2261-2271

Tychkov I. I., Sviderskaya I. V., Babushkina E. A., Popkova M. I., Vaganov E. A., Shishov V. V. (2019) How can the parameterization of a process-based model help us understand real tree-ring growth? Trees, 33 (2): 345-357

Vaganov E. A. (1990) The tracheidogram method in tree-ring analysis and its application. Methods of dendrochronology: applications in the environmental sciences. Dordrecht, Kluwer Academic Publishers, p. 63-75

Vaganov E. A., Hughes M.K., Shashkin A. V. (2006) Growth dynamics of conifer tree rings images of past and future environments. Berlin, Springer, $367 \mathrm{p}$.

Wodzicki T.J. (1971) Mechanism of xylem differentiation in Pinus silvestris L. Journal of Experimental Botany, 22 (3): 670-687

Yang B., He M., Shishov V., Tychkov I., Vaganov E., Rossi S., Ljungqvist F. C., Bräuning A., Grießinger J. (2017) New perspective on spring vegetation phenology and global climate change based on Tibetan Plateau tree-ring data. Proceedings of the National Academy of Sciences of the United States of America, 114 (27): 6966-6971

Ziaco E., Biondi F. (2016) Tree growth cambial phenology and wood anatomy of limber pine at a Great Basin (USA) mountain observatory. Trees, 30 (5): 1507-1521 